\title{
COASTAL GEOLOGY AND OIL SPILLS
}

by

\section{Patrick McLaren}

The catastrophic effects of accidental oil spills warrant scientific concern and coordinated interdisciplinary research on an international scale. Geological input is fundamental, not only in assessing the susceptibility of coastal environments to oil pollution, but in establishing rational contingency plans to cope with potential spills and blow-outs.

\section{Introduction}

In a world increasingly more dependent on offshore drilling for the exploration and exploitation of hydrocarbon reserves, and where economics dictate petroleum transport in hitherto unimaginable quantity, few countries with coastlines can ignore the threat of an oil spill. Contingency plans to cope with oil spills have achieved such a degree of complexity in some of the developed countries that their realistic implementation may be impossible (Donohoe, 1981). Such plans attempt to assess responsibility, assign appropriate authority, identify necessary technical experts and use all the physical, biological and socioeconomic information available to make two fundamental decisions:

- where should a coastline be protected when under an oil spill threat?

- if contaminated, how and where, if at all, should cleanup proceed?

These decisions are not simple. Does a tourist beach take precedence over an oyster farm, or a gull colony over a seal rookery? Is it more important to clean a biologically sensitive habitat such as a marsh, than it is to concentrate efforts on waterfront property? To be effective, a contingency plan must not only have a large, diverse, readily accessible data base, but it must also have a system whereby the data are evaluated and weighted in some rational (though probably arbitrary) scheme to ensure on-the-spot decisionmaking.

Of all the kinds of data required, probably the most fundamental, simplest to obtain and easiest to evaluate are the physical properties of the coast, namely its geomorphology and sedimentology. Unlike biological parameters, temporal variation is not great. Unlike socio-economic considerations, interpretation of the data for decision-making purposes is not complex. Yet this information is so essential that it should form the basic building block of a protection-cleanup contingency plan.

At present, the U.S.A. and Canada probably lead in oil spill research, and much of their coastline has already been mapped with respect to environmental sensitivity. Other countries, such as Norway, Sweden, France, the F.R.G. and the U.K. are also concerned with oil spill countermeasure programs. Unfortunately, there are few instances on record where geological advice has been actively sought during a catastrophe; as a result there are numerous examples where cleanup procedures have either been costly due to re-contamination problems, or have led to even greater environmental damage, or were unnecessary altogether.

The purpose of this paper is to demonstrate how coastal geology may be used in providing answers to questions such as: (i) which coastal environments is the oil most likely to contaminate? (ii) what will be the relative longevity of oil at the shoreline? (iii) is burial or erosion of the oil likely? (iv) what effects will cleanup operations have on the environment? ( $v$ ) if cleanup is to take place, is re-contamination from nearby shoreline environments likely? and (vi) what kind of cleanup technique is most suitable for the contaminated environment?

\section{Rationale}

In general, the characteristics of a coast as defined by its geomorphology and sedimentology share a complex interrelationship with the existing shoreline processes, such as waves, tides, currents, and ice activity (Fig. 1). The latter,

EPISODES, Vol. 1981, No. 3.

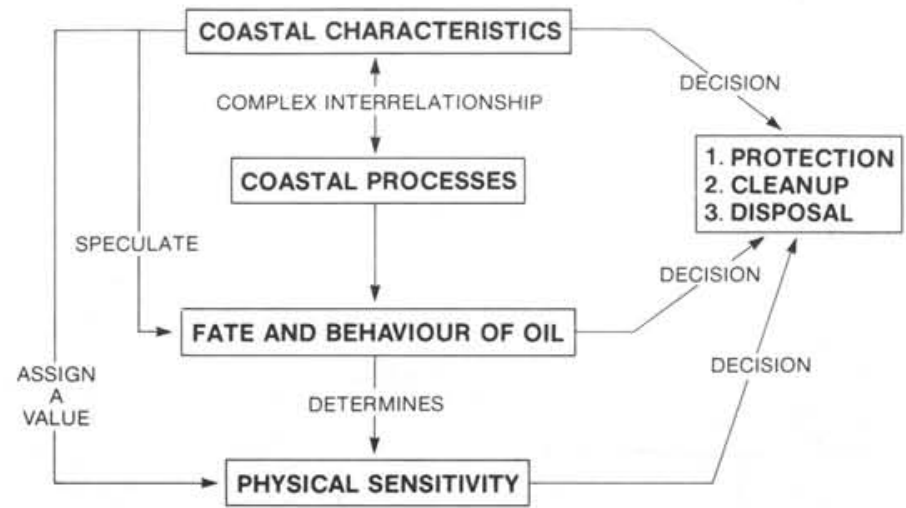

Figure 1. Schematic of the rationale for using coastal geology in oil spill contingency planning.

while paramount in determining the probable fate and behaviour of oil stranded on a shoreline, are not readily useful for oil spill contingency planning. First, the nature and magnitude of the processes are difficult to determine without longterm study, and second, their complexity and temporal variation are difficult to map effectively or to assimilate easily.

The geologist must therefore rely on coastal characteristics to infer processes enabling speculation on the fate and behaviour of oil, and thus provide the basis for decisionmaking (Fig. 1). Depending on the rationale of the scheme used to delineate the coastal characteristics and the subsequent conclusions with respect to the fate and behaviour of oil, it may be useful to simplify the findings with some kind of qualitative sensitivity rating as shown in Figure 1.

\section{Geomorphology}

A coastline can be described by numerous geomorphologic criteria. For contingency planning, criteria should be chosen for their information with respect to the fate, behaviour and cleanup of oil. For example, the slope of coastal features, both on a large scale (such as an average slope from the water line to a fixed distance or elevation onshore), as well as on specific features (such as a beach face), will affect the mechanical energy available to abrade and disperse oil deposited on a shoreline. On steep or cliffed coasts, wave energy will be dissipated in a relatively narrow zone. Incoming

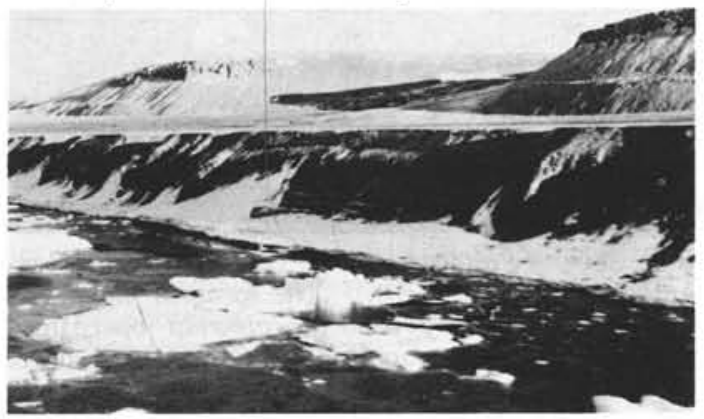

Figure 2. Example of a steep eroding bluff formed in unconsolidated sediments on northern Baffin Island. Processes are inactive for much of the year due to the presence of ice which is still protecting the shore from waves. Erosion and high wave activity during the short open water season would quickly disperse oil on this shoreline. 
waves may be reflected seawards inhibiting oil deposition. Steep bluffs, particularly in unconsolidated sediments may be indicative of active erosion, suggesting that energy levels are high and sediment removal will result in rapid self-cleaning (Fig. 2).

On rocky coasts, breaking waves can throw oil far above the normal high tide level where it is left to seep down over the rock in thin layers. With decreasing slope, the thickness of oil layers can increase. Irregularities in the rock formed by weathering and fracture patterns can result in oil being trapped during this downslope movement. Depending on the viscosity of the oil, it may be released again during the next flood tide or, if thick from weathering prior to its arrival on the shoreline, it is more likely to remain as a coating on the rocks during subsequent tide cycles (Fig. 3).

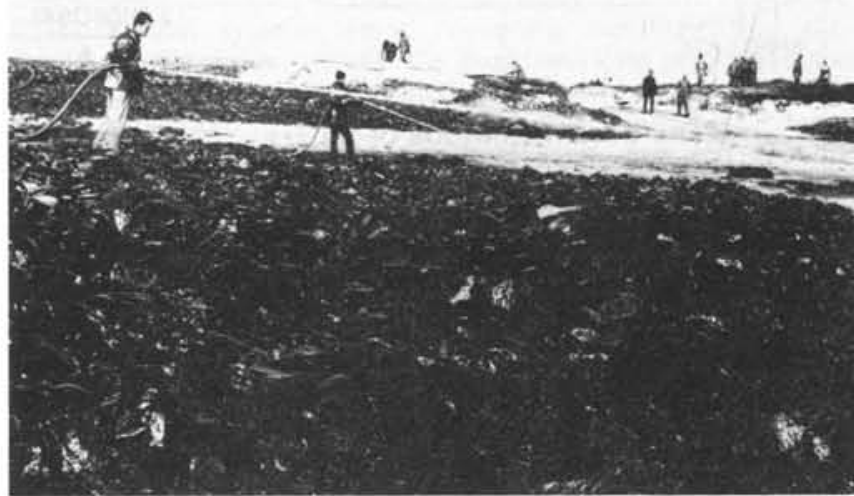

Figure 3. Oiled intertidal rocks on the Brittany coast following the Amoco Cadiz oil spill in the spring of 1978 . The oil was sufficiently viscous from weathering that it could not be lifted off by the incoming tide.

As the slope decreases, the width of the intertidal zone will increase; the consequent attenuation of wave energy will favour oil deposition as well as ensure a longer duration of oil in the shoreline environment. Low coastal slopes favour the formation of depositional shorelines containing biologically important habitats such as deltas and marshes, both of which are excessively difficult to cleanup (Fig. 4). In general, therefore, decreasing slope in the coastal zone results in the following increases: (i) the probability of oil contamination; (ii) longevity of oil in the environment; (iii) aerial extent of contamination; and (iv) cleanup difficulties.

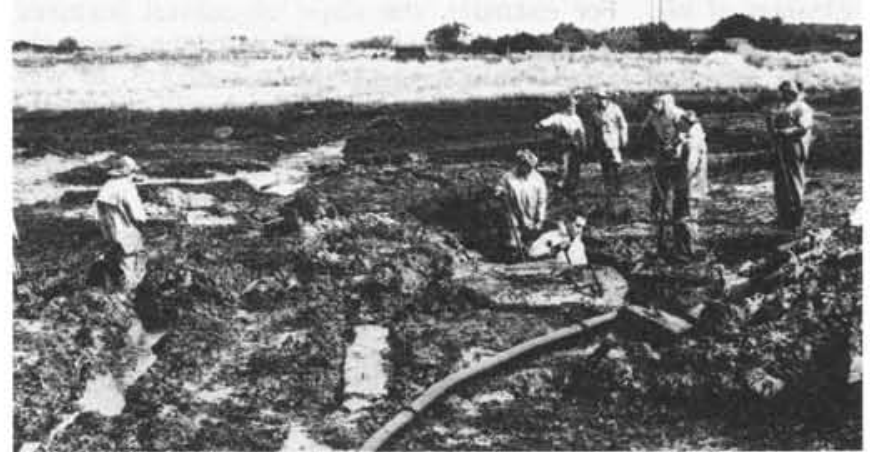

Figure 4. Severely oiled marsh on the coast of Brittany after the Amoco Cadiz oil spill. The grasses have acted as sorbents and machinery used in cleamup operations have resulted in extensive, though inadvertent, mixing of contaminated grass with sediment.

The presence of a beach, defined as the deposit of sediments between low water and the upper limit of marine processes, tends to increase the sensitivity of a coastline by (i) acting as a reservoir for oil which may either penetrate or become buried in the sediments (Vandermeulen et al., 1979; Fig. 5), (ii) disrupting normal beach processes by the possible forma-

EPISODES, Vol. 1981, No. 3.

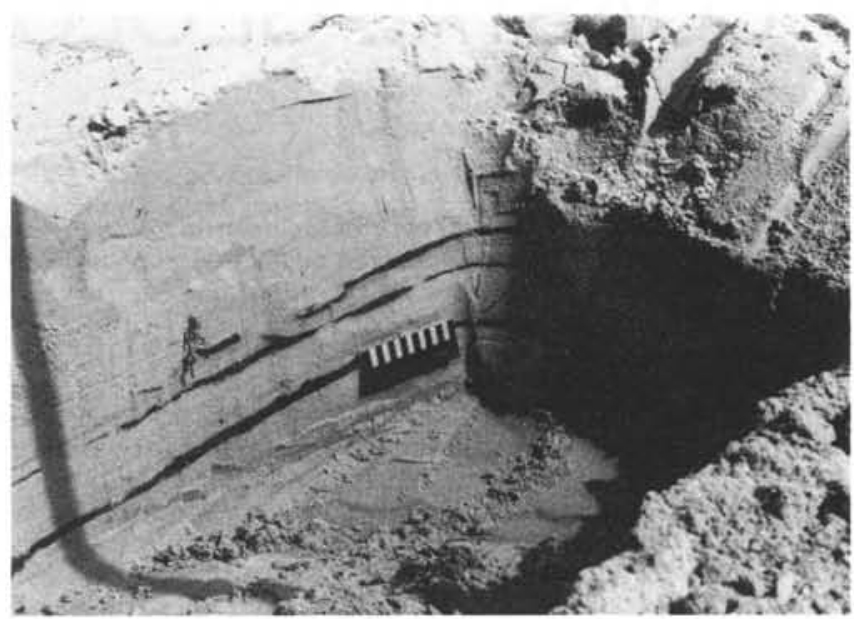

Figure 5. Buried oil in a berm on the Brittany coast af ter the Amoco Cadiz oil spill. There have been three episodes of contamination and subsequent burial.

tion of an asphalt (Owens, 1977), and (iii) responding unfavourably to cleanup procedures as, for example, when sediment removal results in erosion problems (Owens and Rashid, 1976). The component parts of a beach (Fig. 6) may also be used in the assessment of relative shoreline sensitivity. For example, the width of the backshore, beach face and intertidal flat all reflect relative energy regimes and indicate the extent of potential contamination (McLaren et al., 1981).



Figure 6. Example of a beach profile defining the component parts. Comparisons of profiles can be used in determining relative sensitivity.

In areas of abundant sediment supply, features such as spits and tombolos identify regions of accumulation and suggest probable directions and final destination of oil movement (Fig. 7). Barrier beaches frequently protect more vulnerable

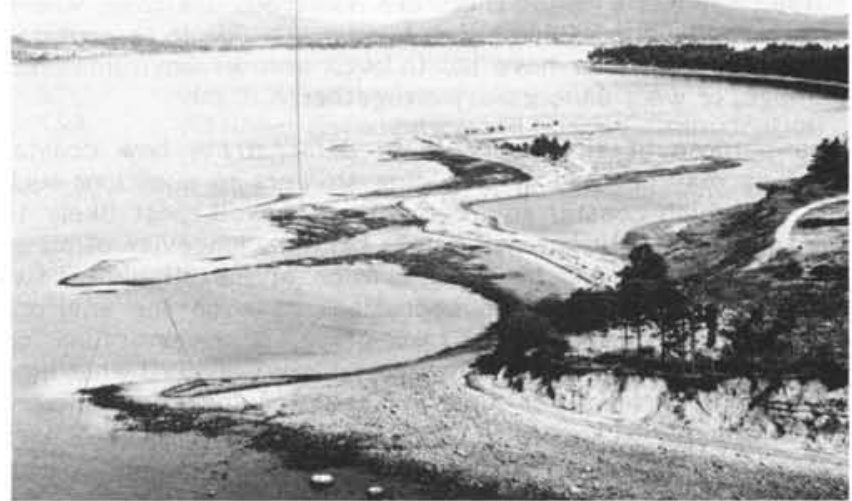

Figure 7. A spit produced from the sediment released in the eroding bluffs. The spit not only suggests the probable direction of oil movement but also shelters a more sensitive, lower energy environment containing fringe marshes. 


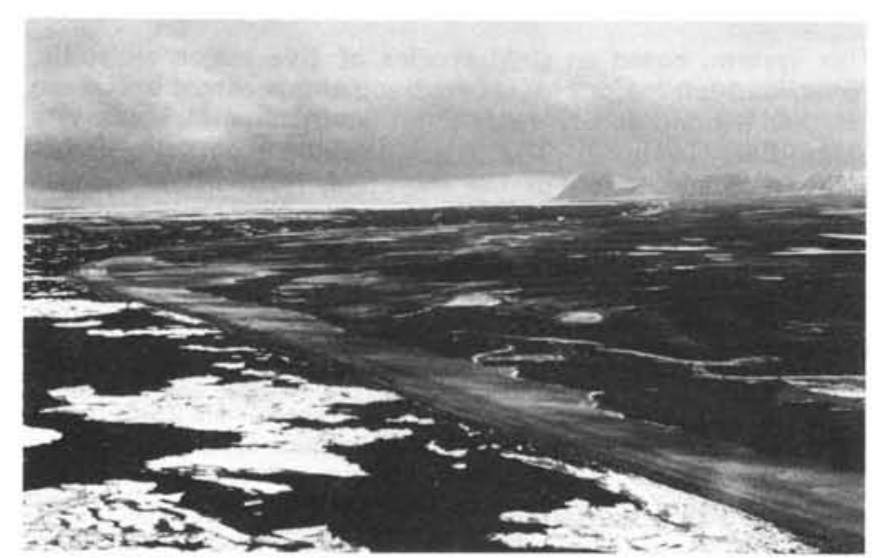

Figure 8. A barrier beach on the north coast of Bylot Island, Northwest Territories. Except in extreme conditions, such barriers will protect the usually more sensitive lagoons from contamination.

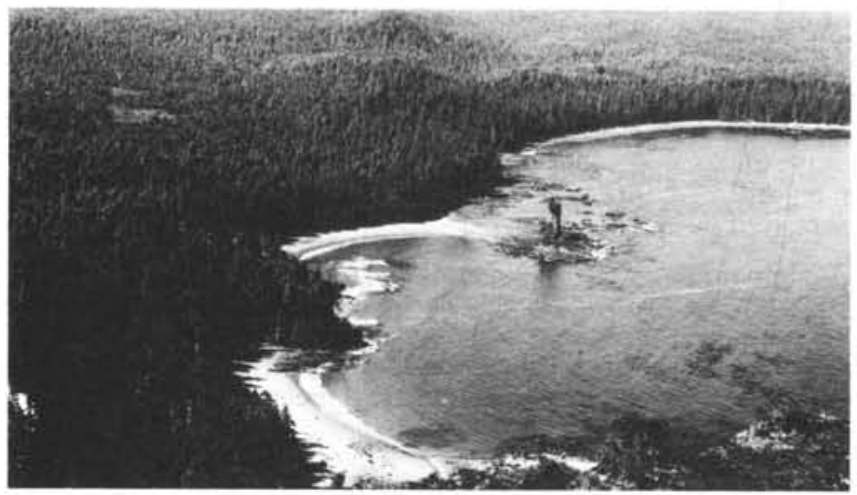

Figure 9. Pocket beaches on the north coast of the Queen Charlotte Islands, British Columbia.

marsh and lagoon environments which are likely to be contaminated only in extreme conditions (Fig. 8). Pocket beaches, on the other hand, occur on rock coasts where the small amount of available sediment becomes trapped between headlands (Fig. 9). Oil will tend to accumulate on such beaches and, because of the limited supply of sediment, cleanup by material removal can cause erosion problems. Furthermore, oil released from the rocky headlands during later tide cycles or storm activity frequently results in their re-contamination (Owens, 1977).

\section{Sedimentology}

The nature of coastal sediments may determine both the behaviour of the oil and the cleanup techniques required. In general, coarser and better sorted sediments have a greater permeability and porosity than those which are finer and more poorly sorted. Studies at the 1978 Amoco Cadiz oil spill (France) showed that coarse-grained permeable beaches were able to retain large quantities of oil which, in spite of cleanup operations, was still present three years after the spill (Long et al., 1981). On fine-grained sand beaches, however, burial of oil was minor and either mechanical cleanup was easily accomplished or the oil was rapidly removed by wave activity (Gundlach et al., 1981).

The method and effectiveness of cleanup techniques are also largely dependent on the sediment characteristics of the contaminated environment. For example, Owens (1977), in a summary of shoreline restoration methods, listed only one recommended method to clean coarse sediment beaches (manual removal), whereas in finer sands, sorbents and mechanical cleanup can also be effective. Similarly for intertidal sediments, mud and fine sand have no recommended cleanup procedure, whereas manual removal is possible for coarser sediments. Contingency planning must therefore take into account sediment texture and be incorporated into a shoreline mapping scheme to assess the physical sensitivity of coastal environments.

EPISODES, Vol. 1981, No. 3.
Grain size characteristics may also be used to determine transport paths for sediment movement which, by inference, can indicate the probable direction that oil will take and/or the fate of the oil in the coastal environment (McLaren, 1980b). This technique requires an analysis of relative trends among the mean grain size, sorting and skewness of sediments from a system of related environments. In effect, the sediments represent an integration of time dependent variables such as winds, waves and currents and, like oil spill trajectory models, suggest the most probable path that oil may take (McLaren et al., 1981).

For example, on the south coast of Vancouver Island, Canada, a spit shelters the Esquimalt Lagoon, a productive habitat bounded by fresh and salt marsh (Fig. 10). Large numbers of fish, including salmon and a population of birds use the lagoon. With such an important environment to protect, a question that might be asked is whether dispersants should be used to protect the lagoon from contamination, or if it is safer to leave the oil stranded on the beach for later cleanup?

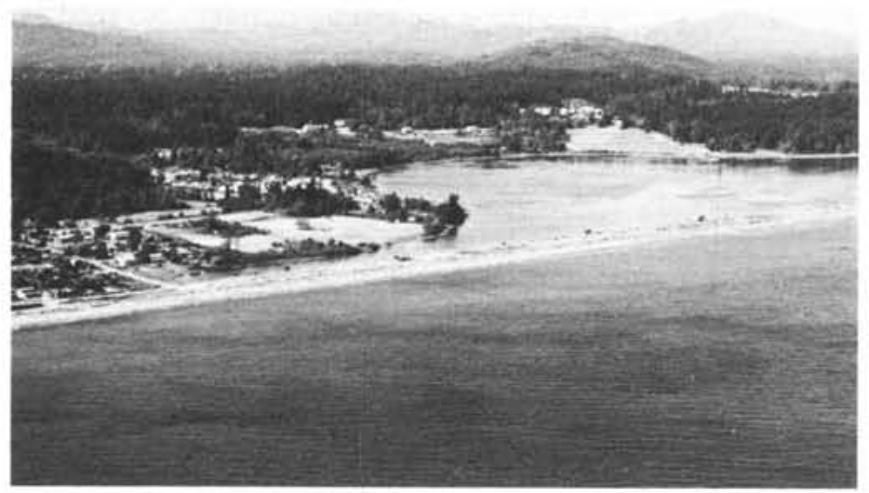

Figure 10. Esquimalt Lagoon on the south coast of Vancouver Island. Sediment distributions within the lagoon suggest that dispersed oil will not be a threat to this environment.

A sediment trend analysis clearly showed that eroding till bluffs were providing the sediment for the north trending spit. Furthermore, beach face sediments became coarser, suggesting that fines were perhaps being flushed into the lagoon through a tidal channel and ultimately deposited. This, however, was not the case, since a comparison of samples from the lagoon with those from the till-beach system indicated no source-deposit relationship. The fines being lost from the spit were apparently not entering the lagoon for final deposition (Collins and May, 1981). It is probable, therefore, that dispersed oil will also not remain within the lagoon to become incorporated into the bottom sediments, and that dispersing an oil slick in the offshore will in all likelihood ensure an uncontaminated lagoon. If left to become stranded on the spit, however, there is a strong probability that floating oil would be swept into the lagoon through the tidal inlet and become trapped by the marsh grass at high tide.

The use of sediment trends appears to offer a rapid and simple method to determine the following: (i) potentially sensitive environments (because there is a high probability of stranded oil becoming buried, resulting in cleanup difficulties and long-term pollution); (ii) environments where there is a high probability of stranded oil being removed by erosion and cleanup may be unnecessary, and (iii) probable littoral drift directions which provide important information on the proper sequence of shoreline cleanup, thus minimizing expenses incurred due to recontamination.

\section{Coastal Mapping}

Like all mapping exercises, coastal mapping shares the common problem of compromising between a suitable scale and the amount of useful information that can be displayed. There is the added difficulty of dealing with an essentially one dimensional coastal strip rather than two dimensional areas. The data base is usually derived from low level 
oblique aerial photographs or, more recently, videotape combined with high level vertical aerial photos, topographic maps and marine charts. Ground observation and sampling is usually essential. Gundlach and Hayes (1978) present a method analyzing extensive stretches of coastline (a modification of the "zonal method" - Hayes et al., 1973), variations of which have met with a great deal of success.
This system, based on field studies of five major oil spills, recognizes ten major coastal environments, each of which are assigned a vulnerability index or an Environmental Sensitivity Index (ESI) (Table 1). The index, dependent on the geomorphology/sedimentology of the shoreline, is an inherent measure of the relative level or magnitude of the coastal processes and thus relates directly to the potential longevity

TABLE 1

Example of Coastal Sensitivity Based on the Effects of the Amoco Cadiz Oil Spill in Brittany, France

Environmental

Sensitivity

Index

Shoreline Type

Exposed rocky headlands

2.

Eroding wave-cut platforms

3.

Fine-grained sand beaches

4.

Coarse-grained sand beaches

5. Mixed sand and gravel beaches

6.

Gravel beaches

7.

Exposed, compacted tidal flats (moderate to high biomass)

Sheltered rocky shores

9.

Sheltered tidal flats

10.

Marshes

(after Gundlach et al., 1981)

Comments

\section{(Duration of Pollution)}

Composed of bedrock with high impinging wave activity; wave reflection kept most of the oil offshore; no cleanup was needed

(days or weeks)

No good example of oil interaction.

Exposed to moderate-to-high wave energy; little penetration into the beach because of compact sand; thin buried layers commonly persisted in depositional areas. (months to 1 year)

Common in semi-sheltered area in Brittany; greater penetration of oil due to coarser substrate; buried oil common ( 1 to 2 years)

Found within some sheltered areas of Brittany; an asphalt pavement formed in some low energy areas of oil deposition. ( 1 to 2 years; more in sheltered areas)

Showed rapid and deep penetration of oil (1 to 2 years)

Oil moved rapidly over the flat surface and was deposited along the swashline; varied biological impact; in productive areas, impact was severe (months to 1 year, oil as sheen evident after 2 years)

Oil sticks to rocky surfaces; pools of oil between the rocks eventually turned to asphalt (up to 5 years, but most obvious oil effects gone after 2 years)

In areas of low wave energy, oil persisted on the surface as mixed oil and sediment patches; contamination of interstitial water persisted even if the surface was cleaned (more than 5 years)

Oil pooled on the surface of the marsh, killing most flora and fauna. Oil was still very obvious 2 years after the spill.

( 5 to 10 or possibly more years)

\section{Observed Cleanup}

Difficult access; natural processes sufficient.

Usually difficult access.

Easy access;

can be cleaned mechanically; buried layers difficult to remove.

Easy access; sand removal may cause beach erosion; difficult to use mechanical means.

Easy access; generally hard surface permitted some cleanup of surface oil; high-pressure hosing without sediment removal recommended.

Generally easy access; removal of sediment not recommended; highpressure spraying with mechanical re-working of sediment into surf zone proved most effective.

Easy access; compact flats cleaned easily mechanically; trenches as part of cleanup may have caused increased oiling of interstitial water (visible after 2 years).

Access varies, but is of ten difficult: high-pressure spraying removed algae and organisms as well as the oil; low-pressure washing as the oil comes onshore may be less damaging biologically.

Access difficult on soft flats; cleanup very difficult and not usually effective; heavy machinery mixed oil into the sediment.

Access varies; heavy equipment further destroyed vegetation and natural drainage patterns; manual cleanup not very effective, but necessary in heavily oiled area. 
of oil in each environment, should there be no cleanup. Developed to encompass shoreline vulnerability for part of the Alaskan coastline (Michel et al., 1978), the system correlated well with observations made on the extensively contaminated Brittany coast following the Amoco Cadiz oil spill (Gundlach et al., 1981).

Several other mapping schemes have been developed or proposed, and workers in this field will appreciate how quickly a system can become complex to the point of no longer being usable. The number of potentially mappable parameters can of ten supercede mapping practicability, and several shoreline maps appear so complicated that they may not be useful at the time of a spill emergency (Barry et al., 1977; Woodward-Clyde, 1980). Computer mapping and analytical techniques offer natural solutions to this problem. Sempels (1981) used computer analyses to simplify a descriptive system discussed below. In this case, the computer simply saved large amounts of time in analyzing the enormous numbers of permutations and combinations present in the coastal description. Such a system is particularly useful for contingency planning because it readily indicates the amount of coastline containing sand beaches or rocky headlands between any given locations.

Owens et al. (1981) propose a mapping system in which physical coastal information is coded for storage on computer files for quick retrieval and analysis. They have attempted to make the system multi-user oriented by including on the coding sheets not only geomorphologic and sedimentologic criteria, but process information as well. Until such a system is integrated with computer mapping techniques to display specific data as well as to amalgamate the enormous numbers of parameters into a useable sensitivity index, there is a danger in the system being too complicated for rapid use.

In a regional study encompassing over $10000 \mathrm{~km}$ of the Labrador shoreline, McLaren (1980a) developed a descriptive system designed to ensure that: (i) each part of the description was informative with respect to the behaviour and cleanup of oil; (ii) the importance of the components was easily assessed; (iii) unforeseen parameters could be incorporated into the system during the mapping, and (iv) the maps were simple to understand (Table 2, Fig. 11).

\section{TABLE 2}

Descriptive Legend for the Coasts of Labrador (after McLaren, 1980a)

\section{Prefix}

s - steep (cliff) slope

m - moderate slope

1 - low slope

s - steep (cliff) slope

m - moderate slope

1 - low slope

$v$ - veneer

$\mathrm{p}$ - pocket

c - continuous

$n$ - narrow $(<100 \mathrm{~m})$

I - intertidal

$$
\begin{aligned}
& \text { Characteristic } \\
& \mathrm{R} \text { - coast is constructed } \\
& \text { in bedrock }
\end{aligned}
$$

Suffix

$$
\begin{aligned}
& U-\text { coast is constructed } \\
& \text { in unconsolidated } \\
& \text { material }
\end{aligned}
$$

b - boulder

$s$ - sand

g-gravel

c - cobble

b - boulder

bb - boulder barricade
B - beach

Note: Three symbols separate the characteristics

(i) $1<20 \%$

(ii) $-20 \%$ to $80 \%$

(iii) : $>80 \%$

eg. $\mathrm{mU}: \mathrm{cBg}$ - wIbb. The mappable unit is moderately sloping, unconsolidated coastline; it contains at least $80 \%$ continuous gravel beach, and wide intertidal flats with a boulder barricade occur from $20 \%$ to $80 \%$ of the length of the unit.

EPISODES, Vol. 1981, No. 3.

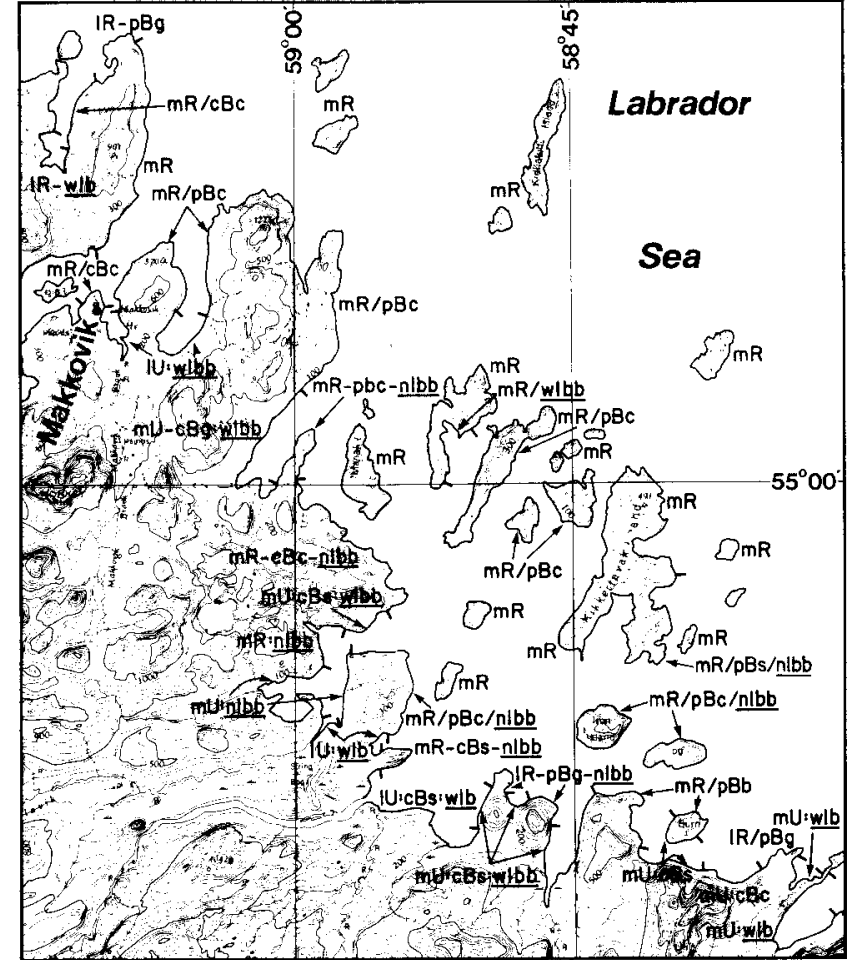

Figure 11. Example of a shoreline map from the Labrador coast. Legend is explained in Table 2.

Using the elements of the description in Table 2, the shoreIine was ranked with respect to physical sensitivity using an empirically derived set of values (Table 3 ) which, in turn, provided a rationale for a physical sensitivity map (Fig. 12). The latter term is defined as a relative measure of the seriousness of oil pollution in a particular environment with respect to the probable dispersal of oil, residence time and cleanup difficulties. Physical sensitivity maps enable rapid determination of the environments that warrant protection, whereas, if oil does pollute the coast, the descriptive maps provide a basis for the cleanup procedures.

\section{Conclusions}

Oil spill contingency planning has become an important issue in most countries concerned with the exploration and transport of hydrocarbons. Oil that has drifted onto shorelines has serious environmental, economic and social consequences. Both countermeasure planning and cleanup techniques require a knowledge of the physical characteristics of the shoreline as defined by its geomorphology and sedimentology. Such information can be used to:

(i) assess the relative sensitivity of shorelines,

(ii) plan effective countermeasure programs,

(iii) determine the probable longevity of oil in contaminated coastal environments,

(iv) define the probable patterns of movement of oil in the coastal zone, and

(v) provide the basis for suitable cleanup techniques.

For oil spill contingency planning, the geomorphic and sedimentologic characteristics of a shoreline are best presented on maps which delineate both the relative sensitivity of shoreline environments and the nature of the shoreline in sufficient detail to provide the basis for a cleanup strategy. Care must be taken, however, to keep the rationale and the mapping system sufficiently simple to ensure its usefulness in a catastrophe.

The geological aspects of shorelines are only a part of what may be termed the "total sensitivity" of a coastal environment, and the information derived from geology should be amalgamated with the biological consequences of oil spill. Future effort in countermeasure programs could be greatly enhanced by a closer association between these two disciplines. 


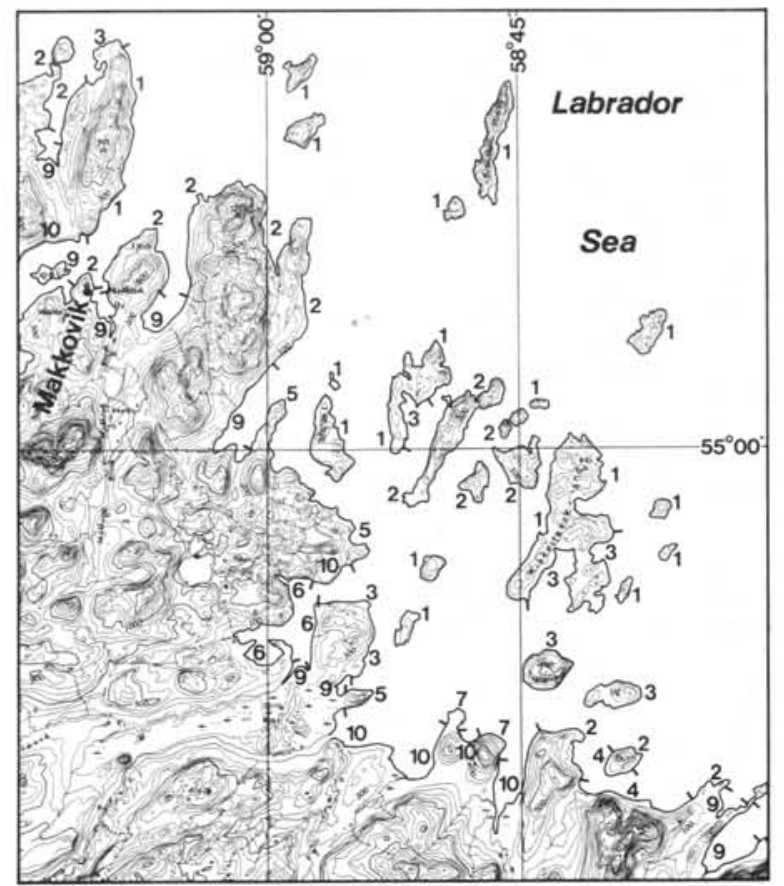

Figure 12. Example of the same shoreline as in Figure 2 with the coastal description converted to a physical sensitivity scale (see Table 3). As the physical sensitivity of the coast increases from 1 to 10 the following also increase: (i) the amount of potential coastal contamination, (ii) storage capabilities of hydrocarbons in the environment, (iii) residence time, (iv) cleanup difficulties and ( $v$ ) potential environmental damage by cleanup operations.
TABLE 3

Values Applied to Descriptive Legend (Table 2) to Obtain a Physical Sensitivity Ranking (after McLaren, 1980a)

$$
\begin{array}{rlrl}
\mathrm{sR}=1 & \mathrm{sU} & =4 \\
\mathrm{mR}=2 & \mathrm{mU}=5 \\
1 \mathrm{R}=3 & \mathrm{IU}=6 \\
/ \mathrm{vB} & =1 & \\
/ \mathrm{pB} & =2 & \\
/ \mathrm{cB} & =4 & \\
-\mathrm{vB} & =5 & \mathrm{~s}=1 \\
-\mathrm{pB} & =10 & \mathrm{~g}=3 \\
-\mathrm{cB} & =20 & \mathrm{c}=4 \\
: \mathrm{vB} & =9 & \\
: \mathrm{pB} & =18 & \\
: \mathrm{cB} & =36 & \\
/ \mathrm{nI} & =8 & \\
/ \mathrm{wI} & =16 & \\
-\mathrm{nI} & =40 & \mathrm{~b} & =5 \\
-\mathrm{wI} & =80 & \mathrm{bb} & =10 \\
: \mathrm{nI} & =72 & \\
: \mathrm{wI} & =144 &
\end{array}
$$

Values are additive: eg. $\mathrm{IR} / \mathrm{pBs} \cdot \mathrm{wIb}=3+2+2+16+5=28$

\section{References}

Barry, R.G., Krane, R.G., Locke, C.W., Locke, W.W. III and Miller, G.H., 1977, The coastal environment of southern Baffin island and northern Labrador-Ungava: Final report to the Arctic Petroleum Operators Association; Calgary, Alberta, APOA Project 138, Univ. of Colorado, $166 \mathrm{p}$.

Collins, A. and May, N.P., 1981, The impact of a potential oil spill upon Esquimalt Lagoon, Victoria, B.C.: unpubl. report, Univ. of Victoria, B.C., 32 p.

Donohoe, M.J., 1981, Contingency plans: a useful tool or bureaucratic burden?: Proc. 1981 Oil Spill Conference (Prevention, Behaviour, Control, Cleanup), Am. Pet. Inst. (Prevention, Behaviour, Contr.
Publ. No. 4334, p. 513-515.

Gundlach, E.R., Berné, S., D'Ozouville, L. and Topinka, J.A., 1981, Shoreline oil two years after Amoco Cadiz: New complications from Tanio: Proc. 1981 Oil Spill ConferInst. Publ. No. 4334, p. 525-534.

Gundlach, E.R. and Hayes, M.O., 1978, Vulnerability of coastal environments to oil spill impacts: Mar. Tech. Soc. J., 12, No. 4, p.18-27.

Hayes, M.O., Owens, E.H., Hubbard, D.K. and Abele, R.W., 1973, The investigation of form and processes in the coastal zone, in Coates, D.R. (ed.), Coastal Geomorphology: State Univ. of N.Y., Binghampton, N.Y., p.11-41.

Long, B.F.N., Vandermeulen, J.H. and Abern, T.P., 1981, The evolution of stranded oil within sandy beaches: Proceedings of the 1981 Oil Spill Conference (Prevention, Behaviour, Control, Cleanup): Am. Pet. Inst. Publ. No. 4334, p. $519-524$.

McLaren, P., 1980a, The coastal morphology and sedimentology of Labrador: a study of shoreline sensitivity to a potential oil spill: Geol. Surv. Can. Pap. 79-28, 41 p.

McLaren, P., 1980b, Trends in sediment distributions: a method to predict oil spill movement in the coastal zone: Spill Technology Newsletter, Environment Canada, S, No. 3, p. 76-87.

McLaren, P., 1981, An interpretation of trends in grain size measures: J. of Sed. Pet., 51, No. 2, p. 611-624.

McLaren, P., Barrie, W.B., and Sempels, J.M., 1981, The coastal morphology and sedimentology of Cape Hatt: implications for the Baffin Island Oil Spill project (BIOS): Current Research, Part B, Geol. Surv. Can., Paper 81-1B, p. 153-162.

Michel, J., Hayes, M.O, and Brown, P.J., 1978, Application of an oil spill vulnerability index to the shoreline of lower Cook Inlet, Alaska: Envir. Geol., 2, No. 2, p. 107-117.

Owens, E.H., 1977, Coastal environments of Canada: the impact and cleanup of oil spills: Fisheries and Environment Canada, EPS-3-EC-77-13, 413 p.

Owens, E.H. and Rashid, M.A., 1976, Coastal environments and oil spill residues in Chedabucto Bay, Nova Scotia: Can. Journal Earth Sciences, 13, No. 7, p. 908-928.

Owens, E.H., Taylor, R.B., Miles, M. and Forbes, D.L., 1981, Coastal geology mapping: an example from the Sverdrup low land, District of Franklin: Current Research, Part B, Geol. Surv. Can., Paper 81-1B, p. 39-48.

Sempels, J.M., 1981, Coastlines of the eastern Arctic: unpubl. manuscript, Petro-Canada, Calgary, Alberta, in press.

Vandermeulen, J.H., Buckley, D.E., Levy, E.M., Long, B.F., McLaren, P. and Wells, P.G., 1979, Sediment penetration of Amoco Cadiz oil, potential for future release and toxicity: Mar. Poll. Bul., 10, No. 8, p. 222-227.

Woodward-Clyde Consultants, 1980, Coastal geology maps, central Severdrup Basin, Northwest Territories: Geol. Surv. Can., Open File 549 .

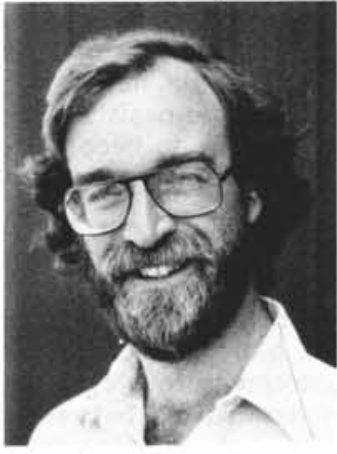

EPISODES, Vol. 1981, No. 3.
ABOUT THE AUTHOR: Dr. Patrick McLaren is a research scientist at the Geological Survey of Canada. He received his doctorate for research on coastal geomorphology and processes in the high arctic. Since then he has applied geological principles to advise the Canadian Department of Environment in oil spill experiments and contingency planning. His current scientific interests include the use of grain size characteristics to determine patterns of movement among related sedimentary environments. 